Pacific Journal of Mathematic 


\section{ON BOUNDED AND SUBCONTINUOUS MULTIFUNCTIONS}

\section{A. LECHICKI}

In this paper we extend Kocela's conditions of boundedness of real valued functions to the case of multifunctions. Moreover the concept of subcontinuity (introduced by R. E. Smithson) is considered with application to the following generalization of a result of Ka-Sing Lau:

Let $F: X \rightarrow Y$ be a point closed and convex multifunction taking values in a locally convex space $Y$ and suppose $F$ is subcontinuous. Then it is $f$-continuous if and only if for every functional $y^{\prime} \in Y^{\prime}$ the function $x \rightarrow \sup \left\{y^{\prime}(y): y \in F(x)\right\}$ is continuous.

1. Let $X, Y$ denote topological spaces. $\mathscr{A}(Y)$ is the family of all nonempty subsets of $Y ; 2^{Y}$ and $\mathscr{C}(Y)$ are the families of closed and compact sets in $\mathscr{A}(Y)$, respectively.

A multifunction $F: X \rightarrow \mathscr{A}(Y)$ is called $f$-upper semicontinuous at $x_{0} \in X\left(f\right.$-usc at $\left.x_{0}\right)$ if for each open set $G$, containing $F\left(x_{0}\right)$ the set $\{x \in X: F(x) \subset G\}$ is open. $F$ is $f$-lower semicontinuous at $x_{0} \in X(f$-lsc at $\left.x_{0}\right)$ if for every open $G$ such that $F\left(x_{0}\right) \cap G \neq \varnothing$ the set $\{x \in X: F(x) \cap$ $G \neq \varnothing\}$ is open. $\quad F$ is $f$-continuous at $x_{0} \in X$ if it is $f$-usc and $f$-lsc at $x_{0} \in X$.

Now let $(Y, \mathfrak{U})$ be an uniform space. For $V \in \mathfrak{U}$ and $A \subset Y$ we denote $V[A]=\{y \in Y:(z, y) \in V$ for some $z \in A\}$. Let $U\left(x_{0}\right)$ denote a base of neighbourhoods of $x_{0} \in X$. We say that a multifunction $F: X \rightarrow \mathscr{A}(Y)$ is $u$-continuous at $x_{0} \in X$ if for every $V \in \mathfrak{A}$ there is $U\left(x_{0}\right) \in U\left(x_{0}\right)$ such that $x \in U\left(x_{0}\right)$ implies

$$
F\left(x_{0}\right) \subset V[F(x)] \text { and } F(x) \subset V\left[F\left(x_{0}\right)\right] .
$$

The grill of $U\left(x_{0}\right)$, denoted by $U^{\prime \prime}\left(x_{0}\right)$, consists of all sets $U^{\prime \prime}\left(x_{0}\right)$ contained in $X$ such that $U^{\prime \prime}\left(x_{0}\right) \cap U\left(x_{0}\right) \neq \varnothing$ for every $U\left(x_{0}\right) \in$ $\mathcal{U}\left(x_{0}\right)$. We say that a multifunction $F: X \rightarrow \mathscr{A}(Y)$ is $p$-upper semicontinuous at $x_{0} \in X\left(p-u s c\right.$ at $\left.x_{0}\right)$ if

$$
p-\limsup _{x \rightarrow x_{0}} F(x)=\bigcap_{U\left(x_{0}\right) \in \mathscr{U}_{\left(x_{0}\right)}}\left[\overline{\bigcup_{x \in U\left(x_{0}\right)} F(x)}\right] \subset F\left(x_{0}\right),
$$


and that $F$ is $p$-lower semicontinuous at $x_{0} \in X\left(p\right.$-lsc at $\left.x_{0}\right)$ if

$$
F\left(x_{0}\right) \subset p-\liminf _{x \rightarrow x_{0}} F(x)=\bigcap_{U^{\prime \prime}\left(x_{0}\right) \in \mathcal{U}^{\prime \prime}\left(x_{0}\right)}\left[\overline{\bigcup_{x \in U^{\prime \prime}\left(x_{0}\right)} F(x)}\right] .
$$

A multifunction $F: X \rightarrow \mathscr{A}(Y)$ is called $p$-continuous at $x_{0} \in X$ if it is $p$-lsc and $p$-usc at $x_{0} . \quad F$ is $p$-usc (i.e. $p$-usc at each $x \in X$ ) iff it has a closed graph $G(F)=\{(x, y) \in X \times Y: y \in F(x)\}$ (Choquet [1]). For more information about these notions of continuity see for example [6].

2. Let $Y$ denote a real Hausdorff topological vector space and $\mathscr{B}(Y)[\mathscr{K}(Y)]$ the collection of nonempty bounded [nonempty closed and convex] subsets of $Y$. A multifunction $F: X \rightarrow \mathscr{A}(Y)$ is called bounded if the set $F(X)=\cup_{x \in X} F(x) \subset Y$ is bounded.

A topological space $X$ is called $\sigma$-absolutely closed [5] if for each open countable cover $\left\{G_{n}\right\}$ there is a finite subset $\left\{G_{1}, \cdots, G_{k}\right\}$ of $\left\{G_{n}\right\}$ such that

$$
X=\overline{\bigcup_{i=1}^{k} G_{i}}
$$

The following three propositions generalize the results of E. Kocela [5] established for real valued functions.

2.1. If $X$ is $\sigma$-absolutely closed then every $f$-continuous multifunction $F: X \rightarrow \mathscr{B}(Y)$ is bounded.

Proof. Let $V$ be a neighbourhood of 0 in $Y$ and $W$ a neighbourhood of 0 such that $\bar{W} \subseteq V$. Define $G_{n}=\{x \in X: F(x) \subset n W\}$, $n \in N$. By assumption $X=\bigcup_{i=1}^{k} G_{i}$, for some $k \in N$. Hence by $f$ lower semicontinuity of $F$ we have

$$
\begin{aligned}
X=\bar{G}_{k}= & \{\overline{x \in X: F(x) \subset k W}\} \subset\{x \in X: F(x) \subset k \bar{W}\} \\
& \subset\{x \in X: F(x) \subset k V\}, \text { i.e., } F(X) \subset k V .
\end{aligned}
$$

A pair of families of sets $\left\{A_{\lambda}\right\},\left\{B_{\lambda}\right\}, \lambda_{0} \leqq \lambda<\infty,\left(\lambda_{0}\right.$ is a fixed real number) is said to satisfy condition (*) if

(1) for every $\lambda \geqq \lambda_{0}$ the set $A_{\lambda}$ is closed while the set $B_{\lambda}$ is open,

(2) for every pair $\lambda_{1}<\lambda_{2}$ holds $A_{\lambda_{1}} \supset B_{\lambda_{1}} \supset A_{\lambda_{2}} \supset B_{\lambda_{2}}$,

(3) $A_{\lambda} \neq \varnothing \neq B_{\lambda}$.

A topological space $X$ is called *-compact if for every pair of families satisfying condition (*) $\cap A_{\lambda}=\cap B_{\lambda} \neq \varnothing$ holds [5]. 
2.2. If $X$ is *-compact and $Y$ is a locally convex space then every $f$-continuous multifunction $F: X \rightarrow \mathscr{B}(Y)$ is bounded.

Proof. Let $\left(p_{t}\right)_{t \in T}$ be a family of seminorms determining the topology of the space $Y$. Suppose that there exists a nonbounded $f$-continuous multifunction $F: X \rightarrow \mathscr{B}(Y)$. Then there is $t \in T$ such that the set $F(X)$ is unbounded in the space $\left(Y, p_{t}\right)$. For every $\lambda \geqq \lambda_{0}>$ 0 we define

$$
\begin{aligned}
& A_{\lambda}=\{x \in X: F(x) \cap(Y-\lambda V) \neq \varnothing\}, \\
& B_{\lambda}=\{x \in X: F(x) \cap(Y-\lambda \bar{V}) \neq \varnothing\},
\end{aligned}
$$

where $V=\left\{y \in Y: p_{t}(y)<1\right\}$. Then the pair of families $\left\{A_{\lambda}\right\},\left\{B_{\lambda}\right\}$ satisfies the condition (*), but $\cap A_{\lambda}=\cap B_{\lambda}=\varnothing$ holds, because $F(x) \in \mathscr{B}(Y)$ for $x \in X$.

2.3. Let $(Y ; \tau)$ be a locally convex space, $(X, \rho)$ a metrizable compact space and $\rho_{1}$ a topology on $X$ stronger than $\rho$. If $\left(X, \rho_{1}\right)$ is *-compact then every $\left(\rho_{1}\right) u$-continuous multifunction $F: X \rightarrow \mathscr{K}(Y) \cap$ $\mathscr{B}(Y)$ is $(\rho) u$-continuous.

Proof. Suppose that $F: X \rightarrow \mathscr{K}(Y) \cap \mathscr{B}(Y)$ is $\left(\rho_{1}\right) u$-continuous but it is not $(\rho) u$-continuous at $x_{0} \in X$. The multifunction $F$ may be considered as a $\left(\rho_{1}\right)$ continuous function taking values in the locally convex topological vector space $(R(Y), r(\tau))$ from Minkowski-Rådström-Hörmander theorem (see e.g. [2; Th.2.1]). Let $\left(p_{t}\right)_{t \in T}$ be a family of seminorms determining the topology $r(\tau)$ of $R(Y)$. Then there is a seminorm $p_{t}$ such that the function $p_{t} \circ F: X \rightarrow R$ is $\left(\rho_{1}\right)$ continuous but it is not $(\rho)$ continuous at $x_{0}$. Thus applying [5; Th. 6] we obtain that $\left(X, \rho_{1}\right)$ is not $*$-compact.

Now let $Y$ be an arbitrary topological space. Following Smithson [8] a multifunction $F: X \rightarrow \mathscr{A}(Y)$ is said to be subcontinuous if and only if whenever $\left(x_{t}\right)_{t \in T}$ is a convergent net in $X$ and $\left(y_{t}\right)_{t \in T}$ is a net in $F(X)=\bigcup_{x \in X} F(x)$ with $y_{t} \in F\left(x_{t}\right)$ then $\left(y_{t}\right)_{t \in T}$ has a convergent subnet.

THEOREM 2.4. (Smithson [8]). Let $F: X \rightarrow \mathscr{A}(Y)$ be a subcontinuous multifunction which has a closed graph (i.e. $F$ is $p$-usc). Then $F$ is $f$-usc and $F: X \rightarrow \mathscr{C}(Y) \cap 2^{Y}$.

In the case $Y$ is regular every $f$-usc multifunction $F: X \rightarrow 2^{Y}$ is $p$-usc ([6], [8]). Moreover 
TheOREM 2.5. Every $f$-usc multifunction $F: X \rightarrow \mathscr{C}(Y)$ is subcontinuous.

Proof. Let $\left(x_{t}\right)_{t \in T}$ be a net in $X$ which is convergent to $x_{0}$, and let $\left(y_{t}\right)_{t \in T}$ be a net with $y_{t} \in F\left(x_{t}\right)$ for each $t \in T$. Next let $\mathscr{F}$ be the filter associated with $\left(y_{t}\right)_{t \in T}$ and $\mathscr{F}_{0}$ be an ultrafilter $\mathscr{F}_{0} \supset \mathscr{F}_{\text {. Then }} \mathscr{F}_{0}$ converges to some point of $F\left(x_{0}\right)$. To see this, suppose that each $y \in F\left(x_{0}\right)$ is contained in an open set $V(y) \notin \mathscr{F}_{0}$. By compactness of $F\left(x_{0}\right)$ there are points $y_{1}, \cdots, y_{n} \in F\left(x_{0}\right)$ such that $F\left(x_{0}\right) \subset$ $\bigcup_{i=1}^{n} V\left(y_{i}\right)$. Then, since $F$ is $f$-usc, there is a neighbourhood $U$ of $x_{0}$ with property $F(U) \subset \bigcup_{i=1}^{n} V\left(y_{t}\right)$. There is $t_{0} \in T$ such that $\left\{y_{t}: t \geqq\right.$ $\left.t_{0}\right\} \subset \cup_{i=1}^{n} V\left(y_{i}\right)$. Thus $\bigcup_{i=1}^{n} V\left(y_{i}\right) \in \mathscr{F}_{0}$. Since $\mathscr{F}_{0}$ is an ultrafilter, it has to contain at least one $V\left(y_{i}\right), 1 \leqq i \leqq n$, but this is impossible.

From Theorem 2.4, the remark following it and [6; 1.2 and 1.18] (see also [7; Th. 3.4]) we get immediately

Corollary 2.6. Let $Y$ be a Hausdorff uniform space. If a multifunction $F: X \rightarrow 2^{Y}$ is subcontinuous then the following statements are equivalent:

(a) $F$ is $p$-continuous.

(b) $F$ is $u$-continuous.

(c) $F$ is $f$-continuous.

Remark. Theorem 2.4 improves a result of $G$. Choquet [1] obtained in the case of compact $Y$. (See also [9; Prop. 8] and [6; Prop. 1.7].)

Henceforth $Y$ denotes a real Hausdorff locally convex vector space under topology $\tau, Y$ ! its topological dual space. If $A \subset Y$ then the support function of $A$ is defined by

$$
y^{\prime} \rightarrow \varphi\left(y^{\prime}, A\right)=\sup \left\{y^{\prime}(y): y \in A\right\}
$$

The following two propositions are easy to prove.

2.7. For every multifunction $F: X \rightarrow \mathscr{A}(Y)$ the following statements are equivalent:

(a) For every $y^{\prime} \in Y^{\prime}$ and $r \in R$ the set $\{x \in X: F(x) \cap H \neq \varnothing\}$, where $H=\left\{y \in Y: y^{\prime}(y)>r\right\}$, is open.

(b) For every $y^{\prime} \in Y^{\prime}$ the function $x \rightarrow \varphi\left(y^{\prime}, F(x)\right)$ is lower semicontinuous.

2.8. Let $F: X \rightarrow \mathscr{A}(Y)$ and consider the following statements: 
(a) For every $y^{\prime} \in Y^{\prime}$ and $r \in R$ the set $\{x \in X: F(x) \subset H\}$, where $H=\left\{y \in Y: y^{\prime}(y)>r\right\}$, is open.

(b) For every $y^{\prime} \in Y^{\prime}$ the function $x \rightarrow \varphi\left(y^{\prime}, F(x)\right)$ is upper semicontinuous.

We have

(i) (a) $\Rightarrow$ (b).

(ii) If $F(x)$ is weakly compact for every $x \in X$, then (b) $\Rightarrow$ (a).

It is easy to show that in general the condition (b) does not imply the following one:

(c) $F$ is $f$-semicontinuous in the topology $\sigma\left(Y, Y^{\prime}\right)$. The implication (b) $\Rightarrow$ (c) holds under additional assumptions on a multifunction F. More exactly

Theorem 2.9. (Valadier [10, 11] and Godet-Thobie [3].) Let [F be a locally bounded multifunction [3] and] for each $x \in X F(x)$ be a convex and weakly compact [bounded] subset of $Y$. Then $F$ is $f$-usc $[f-l s c]$, in the topology $\sigma\left(Y, Y^{\prime}\right)$, iff for every $y^{\prime} \in Y^{\prime}$ the function $x \rightarrow \varphi\left(y^{\prime}, F(x)\right)$ is upper semicontinuous [lower semicontinuous].

An immediate consequence of the above theorem is the following result, due to Ka-Sing Lau:

THeorem 2.10. (Ka-Sing Lau [4].) Suppose $K$ is a compact subset of $Y$. Then a multifunction $F: X \rightarrow \mathscr{K}(K)$ is $f$-lsc if and only if the set $\{x \in X: F(x) \cap H \neq \varnothing\}$ is open for any half space $H=\left\{y \in Y: y^{\prime}(y)>r\right\}$, where $y^{\prime} \in Y^{\prime}, r \in R$.

By using subcontinuity we can get a generalization of this.

THEOREM 2.11. Let $F: X \rightarrow \mathscr{K}(Y)$ be a subcontinuous and locally bounded multifunction. Then it is $f$-lsc if and only if for every $y^{\prime} \in Y^{\prime}$ the function $x \rightarrow \varphi\left(y^{\prime}, F(x)\right)$ is lower semicontinuous.

Proof. The necessity is clear. Suppose now that $F$ is not $f$-lsc at the point $x_{0} \in X$. Let $U\left(x_{0}\right)=\left(U_{t}\right)_{t \in T}$ be a base of neighbourhoods of $x_{0}$ and partial order $U\left(x_{0}\right)$ by inclusion downward. Then there is a point $y_{0} \in F\left(x_{0}\right)$ and a $\tau$-open set $G \ni y_{0}$ such that, for each $t \in T$, the equality $F\left(x_{t}\right) \cap G=\varnothing$ holds for some $x_{t} \in U_{t}$. Without loss of generality we can consider that the net $\left(x_{t}\right)$ converges to $x_{0}$. Let $\mathscr{V}\left(y_{0}\right)$ be a base of neighbourhoods of $y_{0}$ for the topology $\sigma\left(Y, Y^{\prime}\right)$ and partial order $\mathscr{V}\left(y_{0}\right)$ by inclusion downward. Then give $T \times \mathscr{V}\left(y_{0}\right)$ the product partial order. By Theorem 2.9 the mapping $F$ is $f$-lsc with respect to the 
topology $\sigma\left(Y, Y^{\prime}\right)$. It follows that for each $(t, V) \in T \times \mathscr{V}\left(y_{0}\right)$ there is an $s=s(t, V) \in T$ such that $s \geqq t$ and $F\left(x_{s}\right) \cap V \neq \varnothing$. Choose such $x_{s}$ for every element $(t, V)$. Then the net $\left(x_{s}\right)$ is a subnet of $\left(x_{t}\right)$ and converges to $x_{0}$. Let $y_{s} \in F\left(x_{s}\right) \cap V \neq \varnothing$. The net $\left(y_{s}\right)$ has a subnet $\left(y_{s^{\prime}}\right) \sigma$ convergent to $y_{0}$. Now since $F$ is subcontinuous, some subnet $\left(y_{s^{\prime \prime}}\right)$ of $\left(y_{s^{\prime}}\right) \tau$-converges to some $y_{1} \in Y$, and consequently, $\sigma$-converges to $y_{1}$. Thus $y_{0}=y_{1}$. Since $y_{s^{\prime \prime}} \in F\left(x_{s^{\prime \prime}}\right) \subset Y-G$ we have $y_{0}=$ $y_{1} \in \overline{Y-G^{\tau}}=Y-G$, but this is impossible because $y_{0} \in G$.

2.12. If $F: X \rightarrow \mathscr{K}(Y)$ and for every $y^{\prime} \in Y^{\prime}$ the function $x \rightarrow \varphi\left(y^{\prime}, F(x)\right)$ is upper semicontinuous then a graph $G(F)$ of $F$ is a closed subset of $X \times\left(Y, \sigma\left(Y, Y^{\prime}\right)\right)\left(\right.$ i.e. $F$ is $p$-usc in the topology $\left.\sigma\left(Y, Y^{\prime}\right)\right)$.

Proof. Let $\left(x_{0}, y_{0}\right) \notin G(F)$, i.e. $y_{0} \notin F\left(x_{0}\right)$. Then by the separation theorem there is $y^{\prime} \in Y^{\prime}$ such that $\varphi\left(y^{\prime}, F\left(x_{0}\right)\right)<\lambda<y^{\prime}\left(y_{0}\right)$ for some $\lambda$. As the mapping $x \rightarrow \varphi\left(y^{\prime}, F(x)\right)$ is upper semicontinuous there is a neighbourhood $U\left(x_{0}\right)$ of $x_{0}$ such that $\varphi\left(y^{\prime}, F(x)\right)<\lambda$ provided $x \in U\left(x_{0}\right)$. Then $U\left(x_{0}\right) \times V\left(y_{0}\right) \subset X \times Y-G(F)$, where $V\left(y_{0}\right)=$ $\left\{y \in Y: y^{\prime}(y)>\lambda\right\} \in \sigma\left(Y, Y^{\prime}\right)$.

THEOREM 2.13. Let $F: X \rightarrow \mathscr{K}(Y)$ be a subcontinuous multifunction. Then it is $f$-usc if and only if for every $y^{\prime} \in Y^{\prime}$ the function $x \rightarrow \varphi\left(y^{\prime}, F(x)\right)$ is upper semicontinuous.

COROllary 2.14. Let $X$ be a locally compact space and $F: X \rightarrow \mathscr{K}(Y)$ a subcontinuous multifunction. Then it is $f$-continuous if and only if for every $y^{\prime} \in Y^{\prime}$ the function $x \rightarrow \varphi\left(y^{\prime}, F(x)\right)$ is continuous.

\section{REFERENCES}

1. G. Choquet, Convergences, Grenoble Univ. Annal., 23 (1947), 57-112.

2. L. Drewnowski, Additive and countable additive correspondences, Comment. Math., 19 (1976), 25-54.

3. Ch. Godet-Thobie, Multimesures et multimesures de transition, Thèse, L'Universite des Sciences et Techniques du Languedoc. Montpellier (1975).

4. Ka-Sing Lau, A note on lower semicontinuous set-valued maps, Bull. Acad. Polon. Sci. Sér. Math. Astronom. Phys., 24 (1976), 271-273.

5. E. Kocela, Properties of some generalizations of the notion of continuity of function, Fund. Math., 78 (1973), 133-139.

6. A. Lechicki, On continuous and measurable multifunctions, Comment. Math., (to appear).

7. E. Michael, Topologies on spaces of subsets, Trans. Amer. Math. Soc., 71 (1951), 152-182.

8. R. E. Smithson, Subcontinuity for multifunctions, Pacific J. Math., 61 (1975), 283-288.

9. W.L. Strother, Continuous multi-valued functions, Boletim Soc. Matem., São Paulo, 10 (1955), 87-120. 
10. M. Valadier, Contribution à l'analyse convexe, Thèse, (1970) - Paris.

11. - Quelques propértiés des sous-gradientes, I.R.I.A. - nº 6833.

Received November 30, 1976 and in revised form April 21, 1977.

Institute of Mathematics, The Higher Pedagogical School, SZCZECIN, POLAND 



\section{PACIFIC JOURNAL OF MATHEMATICS EDITORS}

ICHARD ARENS (Managing Editor)

niversity of California

os Angeles, CA 90024

\section{. A. BEAUmont}

niversity of Washington

sattle, WA 98105

. C. MOORE

niversity of California

erkeley, CA 94720
J. DUGUNDJI

Department of Mathematics

University of Southern California

Los Angeles, CA 90007

R. FINN AND J. MiLgRAM

Stanford University

Stanford, CA 94305

\section{ASSOCIATE EDITORS}
F. BECKENBACH
B. H. NEUMANN
F. WOLF
K. YosHidA

\section{SUPPORTING INSTITUTIONS}

NIVERSITY OF BRITISH COLUMBIA

UNIVERSITY OF SOUTHERN CALIFORNIA

ALIFORNIA INSTITUTE OF TECHNOLOGY STANFORD UNIVERSITY

NIVERSITY OF CALIFORNIA

ONTANA STATE UNIVERSITY

UNIVERSITY OF HAWAII

NIVERSITY OF NEVADA

UNIVERSITY OF TOKYO

EW MEXICO STATE UNIVERSITY

UNIVERSITY OF UTAH

REGON STATE UNIVERSITY

NIVERSITY OF OREGON

WASHINGTON STATE UNIVERSITY

UNIVERSITY OF WASHINGTON

SAKA UNIVERSITY

AMERICAN MATHEMATICAL SOCIETY

The Supporting Institutions listed above contribute to the cost of publication of this Journal, but they a t owners or publishers and have no responsibility for its contents or policies.

Mathematical papers intended for publication in the Pacific Journal of Mathematics should be in typ Irm or offset-reproduced (not dittoed), double spaced with large margins. Underline Greek letters in re ierman in green, and script in blue. The first paragraph or two must be capable of being used separately as 'nopsis of the entire paper. Items of the bibliography should not be cited there unless absolutely necessary, hich case they must be identified by author and Journal, rather than by item number. Manuscripts, uplicate, may be sent to any one of the four editors. Please classify according to the scheme of Math. Revieu Idex to Vol. 39. All other communications should be addressed to the managing editor, or Elaine Bart Iniversity of California, Los Angeles, California, 90024.

100 reprints are provided free for each article, only if page charges have been substantially pai dditional copies may be obtained at cost in multiples of 50 .

The Pacific Journal of Mathematics is issued monthly as of January 1966. Regular subscription rate: \$72. year (6 Vols., 12 issues). Special rate: $\$ 36.00$ a year to individual members of supporting institutions.

Subscriptions, orders for numbers issued in the last three calendar years, and changes of address should ent to Pacific Journal of Mathematics, 103 Highland Boulevard, Berkeley, California, 94708.

UBLISHED BY PACIFIC JOURNAL OF MATHEMATICS, A NON-PROFIT CORPORATION

Printed at Jerusalem Academic Press, POB 2390, Jerusalem, Israel.

Copyright (C) 1978 Pacific Journal of Mathematics

All Rights Reserved 


\section{Pacific Journal of Mathematics}

\section{Vol. 75, No. $1 \quad$ September, 1978}

Mieczyslaw Altman, General solvability theorems

Denise Amar and Eric Amar, Sur les suites d'interpolation en plusieurs variables ..........................................

Herbert Stanley Bear, Jr. and Gerald Norman Hile, Algebras which satisfy a second order linear partial differential equation ..................

Marilyn Breen, Sets in $R^{d}$ having $(d-2)$-dimensional kernels ............

Gavin Brown and William Moran, Analytic discs in the maximal ideal space

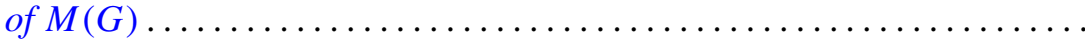

Ronald P. Brown, Quadratic forms with prescribed Stiefel-Whitney

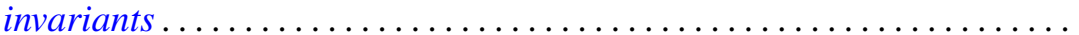

Gulbank D. Chakerian and H. Groemer, On coverings of Euclidean space by convex sets

S. Feigelstock and Z. Schlussel, Principal ideal and Noetherian groups.....

Ralph S. Freese and James Bryant Nation, Projective lattices ............

Harry Gingold, Uniqueness of linear boundary value problems for

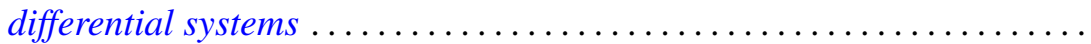

John R. Hedstrom and Evan Green Houston, Jr., Pseudo-valuation domains. . .

William Josephson, Coallocation between lattices with applications to measure extensions

M. Koskela, A characterization of non-negative matrix operators on $l^{p}$ to $l^{q}$ with $\infty>p \geq q>1$

Kurt Kreith and Charles Andrew Swanson, Conjugate points for nonlinear differential equations...........................

Shoji Kyuno, On prime gamma rings ........................ 185

Alois Andreas Lechicki, On bounded and subcontinuous multifunctions ..

Roberto Longo, A simple proof of the existence of modular automorphisms in approximately finite-dimensional von Neumann algebras ...

Kenneth Millett, Obstructions to pseudoisotopy implying isotopy for

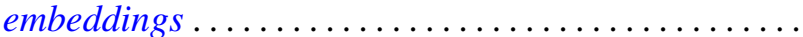

William F. Moss and John Piepenbrink, Positive solutions of elliptic equations. .

Mitsuru Nakai and Leo Sario, Duffin's function and Hadamard's

conjecture

Mohan S. Putcha, Word equations in some geometric semigroups ...

Walter Rudin, Peak-interpolation sets of class $C^{1} \ldots \ldots \ldots$

Elias Saab, On the Radon-Nikodým property in a class of locally convex

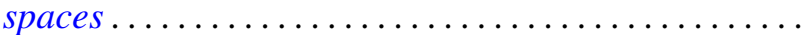

